\title{
Surveillance for hepatocellular carcinoma is associated with increased survival: Results from a large cohort in the Netherlands
}

\author{
Suzanne van Meer ${ }^{1}$, Robert A. de Man $^{2}$, Minneke J. Coenraad ${ }^{3}$, Dave Sprengers ${ }^{2}$, \\ Karin M.J. van Nieuwkerk ${ }^{4}$, Heinz-Josef Klümpen ${ }^{5}$, Peter L.M. Jansen ${ }^{6}$, Jan N.M. IJzermans ${ }^{7}$, \\ Martijn G.H. van Oijen ${ }^{1}$, Peter D. Siersema ${ }^{1}$, Karel J. van Erpecum ${ }^{1, *}$ \\ ${ }^{1}$ Department of Gastroenterology and Hepatology, University Medical Center Utrecht, Utrecht, The Netherlands; ${ }^{2}$ Department of \\ Gastroenterology and Hepatology, Erasmus Medical Center, Rotterdam, The Netherlands; ${ }^{3}$ Department of Gastroenterology and Hepatology, \\ Leiden University Medical Center, Leiden, The Netherlands; ${ }^{4}$ Department of Gastroenterology and Hepatology, VU University Medical Center, \\ Amsterdam, The Netherlands; ${ }^{5}$ Department of Medical Oncology, Academic Medical Center Amsterdam, Amsterdam, The Netherlands; \\ ${ }^{6}$ Department of Gastroenterology and Hepatology, Academic Medical Center Amsterdam, Amsterdam, The Netherlands; ${ }^{7}$ Department of \\ Surgery, Erasmus Medical Center, Rotterdam, The Netherlands
}

Background \& Aims: Effectiveness of surveillance for hepatocellular carcinoma is controversial. We here explore its effects in "real life" clinical practice.

Methods: Patients with hepatocellular carcinoma diagnosed in the period 2005-2012 in five Dutch academic centers were evaluated. Surveillance was defined as $\geqslant 2$ screening tests during three preceding years and at least one radiologic imaging test within 18 months before diagnosis.

Results: 295 (27\%) of 1074 cases underwent surveillance. Median time interval between last negative radiologic imaging and hepatocellular carcinoma diagnosis was 7.5 months. In the surveillance group, cirrhosis ( $97 \%$ vs. $60 \%, p<0.001)$ and viral hepatitis were more frequent, and non-alcoholic fatty liver disease or absence of risk factors less frequent.

In case of surveillance, tumor size was significantly smaller $(2.7 v s .6 .0 \mathrm{~cm})$, with lower alpha-fetoprotein levels (16 vs. $44 \mu \mathrm{g} / \mathrm{L}$ ), earlier tumor stage (BCLC 0 and A combined: $61 \%$ vs. $21 \%$ ) and resection/transplantation (34\% vs. $25 \%$ ) or radiofrequency ablation (23\% vs. $7 \%$ ) more often applied, with significantly higher 1-, 3-, and 5-year survival rates.

Survival benefit by surveillance remained significant after adjustment for lead-time bias based on assumed tumor doubling time of 90 days, but not with doubling time of $\geqslant 120$ days. In multivariate analysis, surveillance was an independent predictor

Keywords: Hepatocellular carcinoma; Surveillance; Survival.

Received 10 September 2014; received in revised form 7 June 2015; accepted 10 June 2015; available online 20 June 2015

* Corresponding author. Address: Department of Gastroenterology and Hepatology, University Medical Center Utrecht, Po BOX 85500, 3508 GA Utrecht, The Netherlands. Tel.: +31 887557004 .

E-mail address: k.j.vanerpecum@umcutrecht.nl (K.J. van Erpecum).

Abbreviations: HCC, Hepatocellular carcinoma; HBV, Hepatitis B virus infection; HCV, Hepatitis C virus infection; US, Ultrasound; AFP, Alpha-fetoprotein; BCLC, Barcelona Clinic Liver Cancer; RFA, Radiofrequency ablation; TACE, Transarterial chemoembolization; TARE, Transarterial radioembolization; HR, Hazard ratio; PS, Performance score. for mortality (for interval $\leqslant 9$ respectively $>9$ months: adjusted HRs 0.51 and $0.50,95 \%$ confidence intervals: $0.39-0.67$ and 0.37-0.69).

Conclusions: Surveillance for hepatocellular carcinoma was associated with smaller tumor size, earlier tumor stage, with an impact on therapeutic strategy and was an independent predictor of survival.

(C) 2015 European Association for the Study of the Liver. Published by Elsevier B.V. All rights reserved.

\section{Introduction}

Liver cancer is the sixth most common cancer in the world and the third cause of cancer-related death [1]. Hepatocellular carcinoma (HCC) represents more than $90 \%$ of primary liver cancers and generally occurs in patients with underlying chronic liver disease. In Western countries with a relatively low incidence rate such as the Netherlands, incidence has increased in the last decade $[2,3]$.

Currently, several international guidelines advise regular surveillance of patients at increased HCC risk [4-6]. The goal is to detect HCC at earlier stages enabling curative therapies with a better outcome and decreased mortality. Nonetheless, surveillance is controversial [7]. One randomized controlled trial from China in chronic hepatitis B (HBV) patients compared surveillance with combined ultrasound (US) and alpha-fetoprotein (AFP) levels at 6-month intervals vs. no surveillance, the study found significantly lower HCC-related mortality rates in the surveillance group [8]. Several aspects of this study have been criticized $[7,9]$. Another randomized controlled study in Chinese HBV patients found no benefit from surveillance with AFP alone at 6 -month intervals [10]. Based on lower quality evidence, several cohort studies suggest improved survival with surveillance (studies summarized in references $[11,12]$ ). 
Conventional US and AFP (alone or combined) are most widely used as surveillance modalities, but their sensitivities and specificities are far from perfect $[13,14]$. Moreover, the optimal surveillance interval is a matter of debate [15-18].

In the present study we investigate the contribution of surveillance in a large group of HCC patients in "real life" clinical practice in the Netherlands.

\section{Patients and methods}

All patients with an HCC diagnosis in the period 2005-2012 in five Dutch academic centers were evaluated. Diagnosis of HCC was based on AASLD 2005 and 2011 guideline criteria [4,19]. Collected data were obtained from (electronic) medical records. Extensive efforts were done to clarify all missing data, e.g. by contacting patients, referring hospitals or general practitioners.

Tumor characteristics, such as number of tumor lesions, maximum diameter of the largest tumor lesion and tumor stage according to Barcelona Clinic Liver Cancer (BCLC) staging system, and laboratory values at time of diagnosis were obtained for each patient. Also, data on ECOG performance status [20], clinical symptoms such as right upper quadrant abdominal pain and weight loss ( $\geqslant 3 \mathrm{~kg}$ ), presence of cirrhosis (based on clinical, laboratory, radiologic, and histologic findings) and cause of underlying liver disease (including HBV and HCV hemochromatosis, alcohol-related liver disease (defined as $\geqslant 3$ alcoholic drinks/day [21]) and non-alcoholic fatty liver disease ([NAFLD] defined as steatosis or steatohepatitis on liver biopsy or presence of metabolic syndrome in the absence of other risk factors for chronic liver disease such as alcohol abuse) were obtained. Severity of liver disease was estimated by calculating the MELD score [22]

Patients were categorized as receiving surveillance (defined as at least two screening tests (AFP and/or imaging test) during the three years before HCC diagnosis and at least one radiologic imaging test within 18 months before diagnosis) or no surveillance. Additionally, time interval (i.e. time between last negative radiological surveillance imaging and date of HCC diagnosis) for patients in the surveillance group was determined. Patients in the surveillance groups were divided into two subgroups based on this time interval: $\leqslant 9$ months and $>9$ months.

Patients were categorized into treatment groups based on application of surgical therapy (resection or transplantation), radiofrequency ablation (RFA) transarterial chemoembolization (TACE) or transarterial radioembolization (TARE), sorafenib or best supportive care. Patients undergoing sequential therapy appertaining to $\geqslant 2$ treatment groups were included in the treatment group presumed to have most impact on outcome. In case of RFA and subsequently TACE, with at least a 1-month interval, patients were included in the RFA group. When combined RFA and TACE were performed within a 1-month interval, patients were included in the TACE group.

This study was in agreement with the Declaration of Helsinki and analyses were performed with institutional medical ethical consent, in an anonymized database.

Statistical analysis

Continuous data are expressed as medians and ranges, and discrete variables as absolute and relative frequencies. Mann-Whitney $U$ or Kruskal-Wallis tests were applied to compare continuous data in various groups. Categorical variables were compared with Pearson's Chi-square or Fisher's exact tests.

Survival time was calculated from date of diagnosis to date of death or end of follow-up (latest: end of study 1-1-2013). To deal with lead-time bias, which represents the apparently improved survival caused by the earlier diagnosis in the course of the disease, we calculated lead-times for all patients who underwent surveillance prior to HCC diagnosis. Lead-time was calculated by using the parametric model proposed by Duffy et al. [23] assuming an exponential distribution of the HCC sojourn time. Calculated lead-time for patients in the surveillance group was subtracted from their survival time.

Kaplan-Meier survival curves and log rank tests were used to compare survival rates between various groups. Apart from HCC surveillance, sex, age, etiology of underlying liver disease, presence of cirrhosis, pain symptoms and weight loss, performance score (PS), year of HCC diagnosis and MELD score were tested as possible predictors for overall mortality by univariate Cox proportional hazard regression analysis. Factors with a $p$ value $<0.05$ in univariate analyses were included in subsequent multivariate analyses. In a separate uni- and multivariate analysis, BCLC stage and applied treatment were also included. Subgroup analyses were performed in cirrhotic patients and in patients in whom

\section{JOURNAL OF HEPATOLOGY}

surveillance is recommended according to AASLD guidelines [4]. A two-sided $p$ value $<0.05$ was considered statistically significant. Statistical analysis was performed using SPSS (version 20).

\section{Results}

\section{Patient characteristics}

In the period January 2005-December 2012, 1288 HCC patients were under care in the five participating hospitals $(60 \%$ of all Dutch HCC patients in this period [3]). After exclusion of 214 patients because of missing data, 1074 (83\%) were included in this study (Fig. 1). Of all included patients, 27\% $(n=295)$ underwent HCC surveillance, without change during the study period. Surveillance was performed by radiological investigations (ultrasound, CT, or MR imaging) alone in $17 \%$ and in combination with AFP in $83 \%$. Median number of surveillance tests in the three years before HCC diagnosis was 7 (range 2-23: 4 (range 1-9) by radiological investigations and 3 (range $0-15$ ) by AFP). Median time interval between last negative radiologic imaging and HCC diagnosis was 7.5 months (range: $0.2-18$ months) ( $\leqslant 9$ months in $60 \%$ of patients and $>9$ months in $40 \%$ ).

Patient characteristics of the total group and separately for the surveillance and non-surveillance groups are given in Table 1. Viral hepatitis was the underlying cause for liver disease in $37 \%$, alcohol abuse in $28 \%$, NAFLD in $16 \%$, hemochromatosis in $2 \%$, and other liver diseases in $3 \%$. Fourteen percent had no risk factors for underlying liver disease, despite extensive investigation for potential causes. Viral hepatitis was more common in the surveillance group ( $61 \%$ vs. $27 \%$ ), whereas NAFLD (7\% vs. $20 \%$ ) or absence of cause(s) for underlying liver disease (3\% vs. $18 \%$ ) were more common in the non-surveillance group. Cirrhosis was present in $97 \%$ of the surveillance and in $60 \%$ of the non-surveillance groups $(p<0.001)$. In the whole group, $93 \%$ of all HCV patients exhibited a cirrhotic liver, which was the case in $75 \%$ of $\mathrm{HBV}$ patients and in $24 \%$ of patients with unknown cause for underlying liver disease. Of the patients without risk factors for underling liver disease $(n=146), 27 \%$ had grade $\leqslant 2$ fibrosis (based on histology), $4 \%$ grade 3 fibrosis (based on

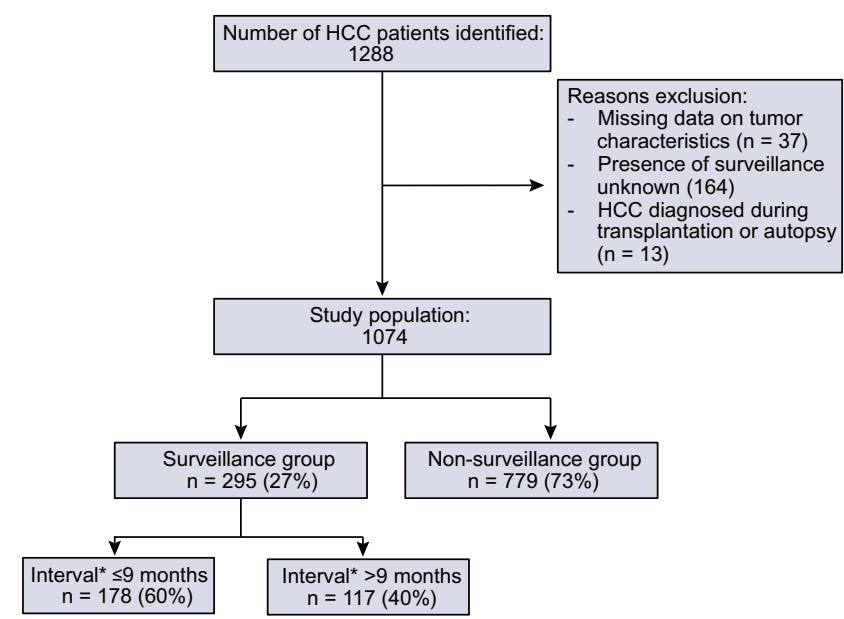

Fig. 1. Flow chart of patient inclusion and details of surveillance. "Time between date of HCC diagnosis and last negative radiologic imaging. 


\section{Research Article}

Table 1. Patient characteristics of 1074 patients with hepatocellular carcinoma with or without previous surveillance.

\begin{tabular}{|c|c|c|c|c|c|c|c|}
\hline & Total group & Surveillance group & $\begin{array}{l}\text { Interval } \leq 9 \\
\text { months }\end{array}$ & $\begin{array}{l}\text { Interval >9 } \\
\text { months }\end{array}$ & $\underset{*}{p}$ value & $\begin{array}{l}\text { Non-surveillance } \\
\text { group }\end{array}$ & $p_{* *}$ value \\
\hline Patient no. & $1074(100)$ & $295(27)$ & $178(60)$ & $117(40)$ & & $779(73)$ & \\
\hline Male gender & $814(76)$ & $229(78)$ & $139(78)$ & $90(77)$ & 0.814 & $585(75)$ & 0.387 \\
\hline $\begin{array}{l}\text { Age at HCC diagnosis } \\
\text { (median, range) }\end{array}$ & $63(8-91)$ & $60(19-90)$ & $60(19-90)$ & $61(29-85)$ & 0.375 & $64(8-91)$ & $<0.001$ \\
\hline Etiology & & & & & 0.348 & & $<0.001$ \\
\hline $\begin{array}{l}\text { Chronic viral hepatitis } \\
\text { Hepatitis B } \\
\text { Hepatitis C } \\
\text { Co-infection }\end{array}$ & $\begin{array}{l}171(16) \\
206(19) \\
16(2)\end{array}$ & $\begin{array}{l}58(20) \\
113(38) \\
8(3)\end{array}$ & $\begin{array}{l}29(16) \\
76(43) \\
4(2)\end{array}$ & $\begin{array}{l}29(25) \\
37(32) \\
4(3)\end{array}$ & & $\begin{array}{l}113(14) \\
93(12) \\
8(1)\end{array}$ & \\
\hline Hemochromatosis & $20(2)$ & $2(1)$ & $1(<1)$ & $1(1)$ & & $18(2)$ & \\
\hline Alcohol & $306(28)$ & $71(24)$ & $42(24)$ & $29(25)$ & & $235(30)$ & \\
\hline NAFLD & $176(16)$ & $22(7)$ & $11(6)$ & $11(9)$ & & $154(20)$ & \\
\hline Others & $33(3)$ & $13(4)$ & $10(6)$ & $3(3)$ & & $20(3)$ & \\
\hline No risk factors known & $146(14)$ & $8(3)$ & $5(3)$ & $3(2)$ & & $138(18)$ & \\
\hline Presence of cirrhosis & $756(70)$ & $286(97)$ & $176(99)$ & $110(94)$ & 0.018 & $470(60)$ & $<0.001$ \\
\hline
\end{tabular}

Results indicate numbers and, between brackets, percentages. ${ }^{*} p$ value applies to differences between the two surveillance interval groups; ${ }^{* *} p$ value applies to differences between the surveillance vs. non-surveillance groups; HCC, hepatocellular carcinoma; co-infection, hepatitis B+C infection. NAFLD, non-alcoholic fatty liver disease.

histology), $24 \%$ cirrhosis (based on histological and/or radiological findings) and $45 \%$ no signs of cirrhosis (based on clinical, laboratory and radiological findings in absence of available histology). Furthermore, proportion of patients $>75$ years old was significantly higher in the non-surveillance group than in the surveillance group ( $17 \%$ vs. $8 \%, p<0.001$ ).

\section{Clinical and tumor characteristics}

As indicated in Table 2, most patients had a single tumor (56\% and $50 \%$ in surveillance and non-surveillance groups, respectively). Nevertheless, patients who did not receive surveillance more often exhibited multifocal or diffuse HCC (35\% vs. $20 \%$, respectively). In the surveillance group, tumor size was significantly smaller $(2.7$ vs. $6.0 \mathrm{~cm} ; p<0.001)$ and HCC was detected in an earlier tumor stage (BCLC 0 and A combined: $61 \%$ vs. $21 \%$ ) than in the non-surveillance group (Table 2).

Performance scores did not differ between surveillance and non-surveillance groups. In the non-surveillance group, right upper quadrant abdominal pain $(36 \%$ vs. $12 \%, p<0.001)$ and weight loss $(25 \% v s .7 \%, p<0.001)$ at time of diagnosis were significantly more common than in the surveillance group (Table 2).

In the surveillance group, median AFP $(16 \mu \mathrm{g} / \mathrm{L} v s .44 \mu \mathrm{g} / \mathrm{L}$; $p<0.001$ ) and ALT levels (44 U/L vs. $49 \mathrm{U} / \mathrm{L} ; p=0.074$ ) were lower than in the non-surveillance group. In contrast, patients who underwent surveillance had higher MELD scores than those in the non-surveillance group (10 vs. 9; $p<0.001$ ) (Table 2). Tumor size and BCLC stage increased with longer surveillance interval (Table 2).

\section{Treatment}

In total, $28 \%$ of all patients received surgical treatment (resection/transplantation), 11\% RFA, 17\% TACE/TARE, $11 \%$ sorafenib and $29 \%$ best supportive care. Details of treatment were not available in $4 \%$. In the surveillance group, surgical treatment (34\% vs. $25 \%$ ) and RFA ( $23 \%$ vs. $7 \%$ ) were more often performed than in patients in the non-surveillance group. In total, $16 \%$ and $17 \%$ of patients in the surveillance and non-surveillance groups respectively, received TACE/TARE. Proportion of patients who received sorafenib was lower in the surveillance group (3\% vs. 14\%). Applied treatments did not differ between the two interval groups (Table 2).

\section{Survival}

Data on vital status were available in 999 patients (93\% of all included patients). The median follow-up after HCC diagnosis was 11 months (range 0.1-95) and was significantly longer in the surveillance group (15 months vs. 10 months). In total, 58\% of all patients $(n=623)$ died during follow-up. Observed 1-, 3-, and 5-year survival rates were significantly higher in the surveillance group than in the non-surveillance group (68\%, 47\%, and $39 \%$ vs. 55\%, 29\%, and $22 \%$, respectively) (Fig. $2, \log$ rank test $p<0.001$ ). When evaluating the survival rates of the two time interval groups separately, both groups had survival benefit compared to the non-surveillance group (hazard ratio (HR) $0.64,95 \% \mathrm{CI} 0.51$ 0.81 for interval $\leqslant 9$ months and HR $0.55,95 \% \mathrm{CI} 0.42-0.73$ for interval $>9$ months). However, there was no significant survival benefit in patients $>75$ years old in the surveillance group compared to the non-surveillance group (HR 0.85 , 95\% CI 0.48-1.50).

Based on assumed HCC median tumor doubling times of 60 days or 90 days, survival benefit for the surveillance group remained significant after adjustment for lead-time bias based on the approach of Duffy et al. [23] (HR 0.74, 95\% CI 0.61-0.90 and HR $0.79,95 \% \mathrm{CI} 0.65-0.95)$. However when HCC tumor doubling time $\geqslant 120$ days was assumed, survival benefit disappeared (HR 0.83, 95\% CI 0.69-1.01).

In multivariate analysis, surveillance was an independent predictor for lower overall mortality (adjusted HR 0.51, 95\% CI $0.39-0.67$ for interval $\leqslant 9$ months and adjusted HR $0.50,95 \% \mathrm{CI}$ $0.37-0.69$ for interval $>9$ months) after adjusting for age, cause of underlying liver disease, presence of cirrhosis, right upper quadrant abdominal pain symptoms and weight loss, PS and MELD score (Table 3). Nevertheless, when also adjusted for BCLC stage and applied treatment, surveillance was no longer an 


\section{JOURNAL OF HEPATOLOGY}

Table 2. Clinical and tumor characteristics of $\mathbf{1 0 7 4}$ patients with hepatocellular carcinoma subdivided according to presence of surveillance prior to HCC diagnosis.

\begin{tabular}{|c|c|c|c|c|c|c|c|}
\hline & Total group & $\begin{array}{l}\text { Surveillance } \\
\text { group }\end{array}$ & $\begin{array}{l}\text { Interval } \leq 9 \\
\text { months }\end{array}$ & $\begin{array}{l}\text { Interval }>9 \\
\text { months }\end{array}$ & $\underset{*}{p \text { value }}$ & $\begin{array}{l}\text { Non-surveillance } \\
\text { group }\end{array}$ & $p_{* \star}^{p}$ value \\
\hline Patient no. & $1074(100)$ & $295(27)$ & $178(60)$ & $117(40)$ & & $779(73)$ & \\
\hline No. of lesions & & & & & 0.856 & & $<0.001$ \\
\hline 1 & $551(51)$ & $165(56)$ & $97(55)$ & $68(58)$ & & $386(50)$ & \\
\hline 2 & $125(12)$ & $52(18)$ & $33(18)$ & $19(16)$ & & $73(9)$ & \\
\hline 3 & $65(6)$ & $18(6)$ & $10(6)$ & $8(7)$ & & $47(6)$ & \\
\hline Multifocal/diffuse & $333(31)$ & $60(20)$ & $38(21)$ & $22(19)$ & & $273(35)$ & \\
\hline Tumor size $(\mathrm{cm})$ & $\begin{array}{l}5.0 \\
(0.8-26.0) \\
\end{array}$ & $\begin{array}{l}2.7 \\
(0.8-17.0)\end{array}$ & $\begin{array}{l}2.5 \\
(0.8-17.0)\end{array}$ & $\begin{array}{l}3.0 \\
(0.8-12.0)\end{array}$ & 0.025 & $\begin{array}{l}6.0 \\
(0.9-26.0)\end{array}$ & $<0.001$ \\
\hline Performance score & & & & & 0.831 & & 0.277 \\
\hline 0 & $382(36)$ & $108(37)$ & $65(37)$ & $43(37)$ & & $274(35)$ & \\
\hline 1 & $354(33)$ & $99(34)$ & $60(34)$ & $39(33)$ & & $255(33)$ & \\
\hline 2 & $115(11)$ & $24(8)$ & $13(7)$ & $11(9)$ & & $91(11)$ & \\
\hline$>2$ & $57(5)$ & $12(4)$ & $9(5)$ & $3(3)$ & & $45(6)$ & \\
\hline Unknown & $166(15)$ & $52(17)$ & $31(17)$ & $21(18)$ & & $114(15)$ & \\
\hline $\begin{array}{l}\text { Right upper quadrant } \\
\text { abdominal pain } \\
\text { Yes } \\
\text { No }\end{array}$ & $\begin{array}{l}318(30) \\
756(70)\end{array}$ & $\begin{array}{l}35(12) \\
260(88)\end{array}$ & $\begin{array}{l}23(13) \\
155(87)\end{array}$ & $\begin{array}{l}12(10) \\
105(90)\end{array}$ & 0.489 & $\begin{array}{l}283(36) \\
496(64)\end{array}$ & $<0.001$ \\
\hline $\begin{array}{l}\text { Weight loss } \\
\text { Yes } \\
\text { No }\end{array}$ & $\begin{array}{l}219(20) \\
885(80)\end{array}$ & $\begin{array}{l}21(7) \\
274(93)\end{array}$ & $\begin{array}{l}13(7) \\
165(93)\end{array}$ & $\begin{array}{l}8(7) \\
109(93)\end{array}$ & 0.879 & $\begin{array}{l}198(25) \\
581(75)\end{array}$ & $<0.001$ \\
\hline BCLC stage & & & & & 0.183 & & $<0.001$ \\
\hline 0 & $65(6)$ & $43(15)$ & $33(19)$ & $10(9)$ & & $22(3)$ & \\
\hline$A$ & $277(26)$ & $136(46)$ & $77(43)$ & $59(50)$ & & $141(18)$ & \\
\hline B & $378(35)$ & $61(21)$ & 34 (19) & $27(23)$ & & $317(41)$ & \\
\hline $\mathrm{C}$ & $273(26)$ & $37(12)$ & $23(13)$ & $14(12)$ & & $236(30)$ & \\
\hline $\mathrm{D}$ & $81(7)$ & $18(6)$ & $11(6)$ & $7(6)$ & & $63(8)$ & \\
\hline $\operatorname{ALT}(\mathrm{U} / \mathrm{L})$ & $47(4-1158)$ & $44(4-445)$ & $45(4-282)$ & $44(14-445)$ & 0.651 & $49(7-1158)$ & 0.074 \\
\hline AFP $(\mu g / L)$ & $\begin{array}{l}28 \\
\left(1-2.7 \times 10^{6}\right)\end{array}$ & $\begin{array}{l}16 \\
\left(1-2.9 \times 10^{5}\right)\end{array}$ & $\begin{array}{l}19 \\
\left(1-2.9 \times 10^{5}\right)\end{array}$ & $\begin{array}{l}12 \\
\left(1-1.9 \times 10^{4}\right)\end{array}$ & 0.092 & $\begin{array}{l}44 \\
\left(1-2.7 \times 10^{6}\right)\end{array}$ & $<0.001$ \\
\hline MELD score & $9(6-33)$ & $10(6-28)$ & $10(6-28)$ & $9(6-20)$ & 0.087 & $9(6-33)$ & $<0.001$ \\
\hline Treatments & & & & & 0.452 & & $<0.001$ \\
\hline $\begin{array}{l}\text { Surgical therapy } \\
\text { Resection } \\
\text { Transplantation } \\
\text { Both }\end{array}$ & $\begin{array}{l}300(28) \\
191(18) \\
104(10) \\
5(<1)\end{array}$ & $\begin{array}{l}101(34) \\
31(10) \\
67(23) \\
3(1)\end{array}$ & $\begin{array}{l}57(32) \\
13(7) \\
44(25) \\
0(0)\end{array}$ & $\begin{array}{l}44(38) \\
18(15) \\
23(20) \\
3(3)\end{array}$ & & $\begin{array}{l}199(25) \\
160(20) \\
37(5) \\
2(<1)\end{array}$ & \\
\hline $\mathrm{RFA}^{\$}$ & $120(11)$ & $66(23)$ & $37(21)$ & $29(25)$ & & $54(7)$ & \\
\hline TACE/TARE^ & $177(17)$ & $48(16)$ & $33(19)$ & $15(13)$ & & $130(17)$ & \\
\hline Sorafenib & $115(11)$ & $10(3)$ & $8(4)$ & $2(2)$ & & $105(14)$ & \\
\hline Best supportive care & $313(29)$ & $62(21)$ & $29(22)$ & $23(19)$ & & $250(32)$ & \\
\hline Unknown & $49(4)$ & $8(3)$ & $4(2)$ & $4(3)$ & & $41(5)$ & \\
\hline
\end{tabular}

Results indicate numbers and, between brackets, percentages; Continuous variables reported as medians and ranges; ${ }^{\$} 9$ patients received RFA and subsequently TACE with more than 1-month interval; ${ }^{\wedge}$ in 28 patients combined TACE and RFA within a 1-month interval was performed as initial therapy; ${ }^{*} p$ value applies to differences between the two surveillance interval groups; ${ }^{* *} p$ value applies to differences between the surveillance vs. non-surveillance groups; BCLC stage, tumor stage according Barcelona Clinic Liver Cancer staging system; ALT, alanine aminotransferase; AFP, alpha-fetoprotein; RFA, radiofrequency ablation; TACE, transarterial chemoembolization; TARE, transarterial radioembolization.

independent predictor for overall mortality (Supplementary Table 1). Analysis in the subgroup of cirrhotic patients (adjusted HR 0.49 , 95\% CI $0.37-0.65$ for interval $\leqslant 9$ months and adjusted HR $0.48,95 \%$ CI $0.35-0.67$ for interval $>9$ months) and in the subgroup of patients in whom surveillance is recommended according to AASLD guidelines (adjusted HR 0.49, 95\% CI 0.37-0.65 for interval $\leqslant 9$ months and adjusted HR $0.49,95 \%$ CI $0.36-0.68$ for interval $>9$ months) yielded similar results. On the other hand, $>62$ years of age, HCV as cause of underlying liver disease, pres- ence of cirrhosis, a worse PS, right upper quadrant abdominal pain, weight loss and a higher MELD score were independent predictors for higher overall mortality (Table 3).

\section{Discussion}

This "real life" study showed that HCC patients who underwent surveillance prior to diagnosis had a smaller tumor size, earlier 


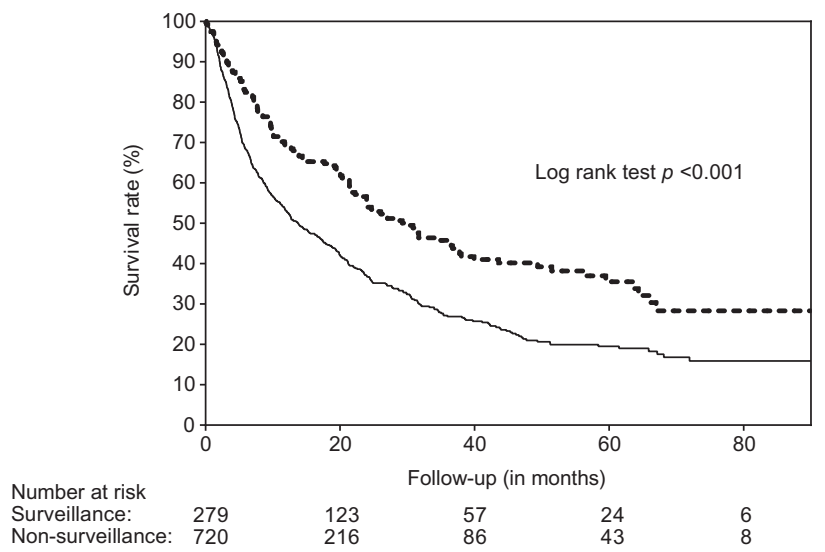

Fig. 2. Observed survival of patients with hepatocellular carcinoma in the surveillance group (dotted line) and non-surveillance group (solid line) $(p<0.001)$.

BCLC tumor stage and lower AFP levels, received more often surgical therapy and had a better overall survival than patients without surveillance. Also, in multivariate analysis, HCC surveillance was found to be an independent predictor of better survival. The findings are in line with previously published retrospective cohort studies, meta-analyses and systematic reviews [11,12]. After additional adjustment for BCLC stage and applied treatment, surveillance was no longer an independent predictor for overall mortality. This interesting finding suggests that surveillance allows better survival through HCC detection in earlier BCLC stage, enabling more effective therapy. Since the two available randomized controlled trials $[8,10]$ on HCC surveillance yielded contradictory results $[9,11]$, lower level of evidence from observational studies could contribute to the advice in current guidelines $[11,13,24]$. Potential limitations of observational studies are length-time bias (i.e. detection of indolent tumors by surveillance) and/or lead-time bias (i.e. detection of tumors in earlier stage by surveillance). Statistical techniques to adjust for lead-time bias were performed in five earlier observational studies [25-29]: in three studies [26-28] the formula of Schwartz et al. [30] was used, whereas the remaining studies [25,29] used the approach of Duffy et al. [23]. In three of these, survival advantage of screening disappeared with assumed tumor doubling times of $\geqslant 90$ days $[25,26,28]$. In line with these data, in the current study survival benefit remained when tumor doubling times of 60 or 90 days was assumed, but disappeared with doubling times $\geqslant 120$ days. We adjusted lead-time bias according to Duffy et al. [23], which may be the most correct method. When we used the formula of Schwartz et al. [30] survival benefit remained significant with assumed tumor doubling time of 60 days, but not with doubling times of 90 or 120 days (HR $0.82,95 \%$ CI 0.68 0.99, HR 0.93, 95\% CI 0.77-1.12 and HR 1.03, 95\% CI 0.86-1.25, respectively).

Based on available data on HCC tumor doubling times, approximately $40 \%$ of HCCs could have a tumor doubling time of less than 90 days [29,31-35]. Nevertheless, this is controversial [36] and further research is needed to evaluate HCC tumor doubling time, to identify possible factors associated with slowand fast-growing tumors and to define the impact of this information on screening strategies. Also, in a recently published study [25] survival benefit of HCC surveillance after correction for lead-time bias became evident after three years follow-up. In the current study, median follow-up time was 11 months.

Interestingly, in most earlier observational studies, patients in the non-surveillance group had more severe liver disease than patients in the surveillance group [11,12]. In contrast, in the current study, liver disease was worse in the surveillance group (cirrhosis in $97 \%$ vs. $60 \%$; $p<0.001$ and MELD score higher: 10 vs. 9; $p<0.001$ ) thus excluding severity of liver disease as a bias explaining observed better survival in our surveillance group. A potential explanation for our relatively low prevalence of cirrhosis in the non-surveillance group could be the relatively large contribution of HCC without risk factors for underlying liver disease (14\% of total) in our cohort (especially in the non-surveillance group). This could be related to the low contribution of viral hepatitis to HCC in the Netherlands with low prevalence of HBV and HCV (both estimated $0.2-0.4 \%$ of the general population [37-39]).

In previous observational studies $60-100 \%$ of patients in the surveillance group and $20-56 \%$ of patients in the non-surveillance group exhibited HCC within Milan criteria [11]. In contrast, $61 \%$ of our surveillance group and $21 \%$ of our non-surveillance group had HCC within Milan criteria. Resection was performed in $10 \%$ of our surveillance group vs. $20 \%$ in our non-surveillance group (3-24\% in previously published surveillance groups [11]) and transplantation in $23 \%$ of our surveillance group $v$ s. $5 \%$ of our non-surveillance group (1-30\% in previously published surveillance groups [11]). Differences in treatment modalities applied in the current vs. previous studies could be due, at least in part, to the high percentage (97\%) of cirrhotic patients in our surveillance group and the relatively large contribution of patients without underlying liver disease (favoring resection) in our non-surveillance group.

In the current report, observed 1-, 3-, and 5-year survival rates were $68 \%, 47 \%$ and $39 \%$ vs. $55 \%, 29 \%$, and $22 \%$ in the surveillance $v s$. non-surveillance group, respectively. Other studies also reported better survival in the surveillance group than in the non-surveillance group. For comparison, previously reported pooled 3-year survival rate of 36 studies was $51 \%$ in surveillance groups vs. $28 \%$ in non-surveillance groups [12]. However, there was no significant survival benefit in our patients $>75$ years old who underwent surveillance. Probably, older patients are less likely candidates for curative surgical treatment. Therefore the cost benefit for surveillance in elderly patients needs further investigations.

Recall strategy and adherence to follow-up are important factors for success of a surveillance program $[40,41]$. A large retrospective cohort study in HCC patients with a prior diagnosis of cirrhosis demonstrated that only $17 \%$ received regular and $38 \%$ inconsistent surveillance [40]. Utilization of surveillance declined with time. In the current study median time interval between previous negative surveillance imaging and HCC diagnosis (7.5 months) was significantly longer than the surveillance interval of 6 months that is advised in the current guidelines [4-6], indicating that surveillance programs can be improved. Furthermore, $62 \%$ of patients in the non-surveillance group had an indication for HCC surveillance based on AASLD guideline criteria $[4,19]$. However, in the majority of these patients presence of liver disease was unknown. In the current study, virtually all patients received surveillance by US, with or without concomitant AFP. Surveillance was associated with survival benefit in subgroups with surveillance interval $\leqslant 9$ months as well as 


\section{JOURNAL OF HEPATOLOGY}

Table 3. Relation between patient/tumor characteristics and mortality in HCC patients in the Netherlands: univariate and multivariate Cox proportional hazard regression analyses.

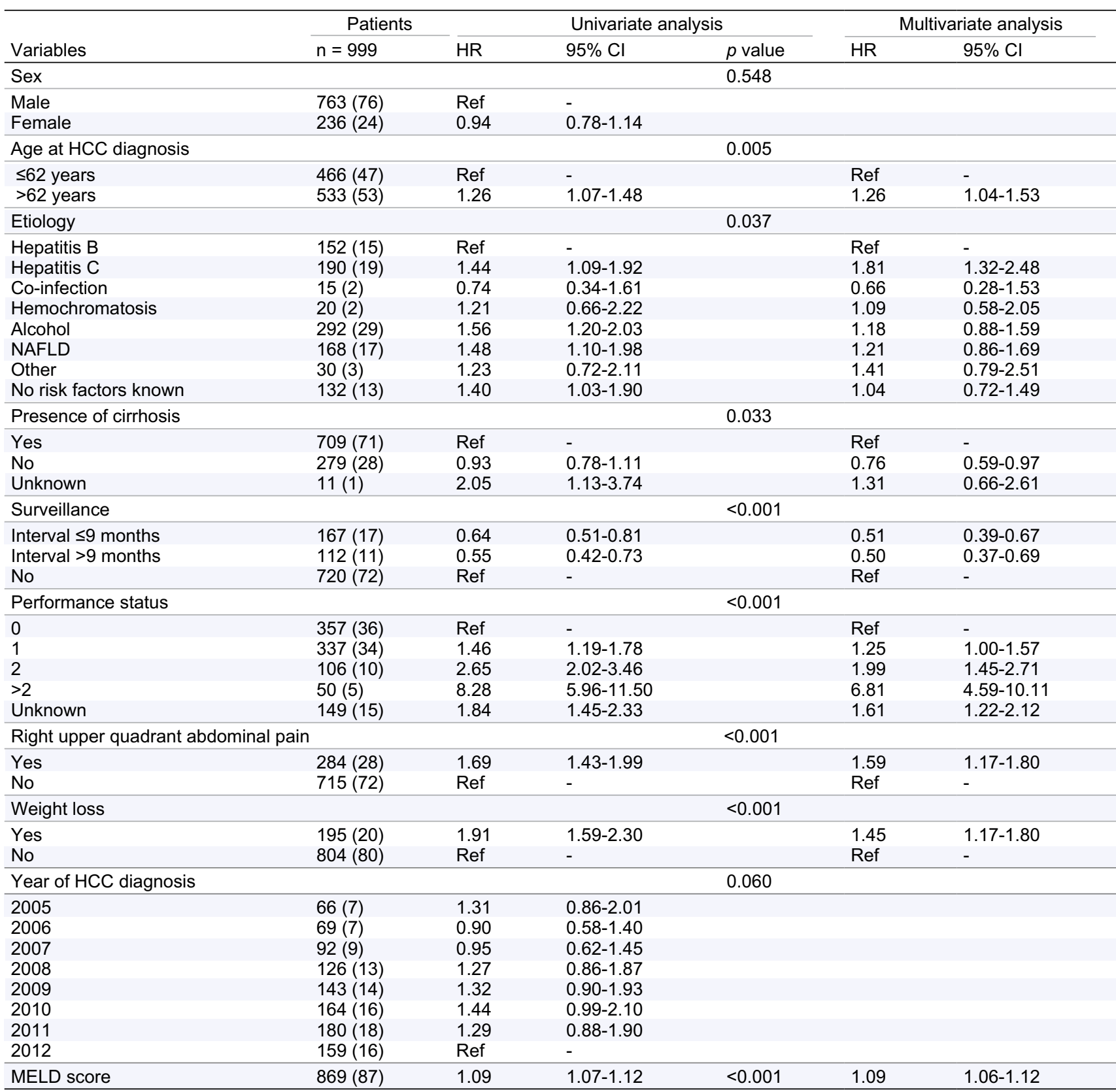

Values in parentheses are percentages; Co-infection, hepatitis B+C infection; NAFLD, non-alcoholic fatty liver disease.

surveillance interval $>9-18$ months, despite significantly larger tumor sizes in the latter group. Potential explanations could be that many tumors in the latter group exceeded limit of ultrasonographic detection only after prolonged time periods after last negative radiological surveillance imaging and/or relatively slow tumor growth. Similar findings were reported in a study from Taiwan comparing 4- and 12-month US screening intervals [17]. We cannot exclude that strict surveillance based on the recommended interval of 6 months could lead to better outcomes, although this is difficult to achieve in clinical practice $[40,42]$.

In the current study, survival was not only determined by tumor features and treatment. Older age, HCV as cause of underlying disease and higher MELD scores were independent predictors for higher overall mortality. One previous study also reported a positive correlation between age and mortality [15], but this was not confirmed in other studies [16,43]. Although Trevisani et al. [43] suggested that prognosis is independent of etiology of liver disease, several other studies indicated that cause of underlying liver disease is an independent risk factor for higher mortality in HCC patients in line with our results [44-46].

The strength of our study is that a large cohort of Western HCC patients was included to examine the effect of surveillance in "real life" clinical practice. Also, there appears to be no bias 


\section{Research Article}

from overrepresentation of cirrhosis in the group without surveillance (in our study, cirrhosis prevalence was higher in the surveillance group). However, findings of this study are inherently limited by the retrospective study design. Despite correction for lead-time bias, surveillance might still preferentially detect slowly growing indolent tumors (length-time bias). Only patients who were diagnosed or referred to one of the five Dutch academic centers were included. HCC patients with a very poor prognosis could not have been referred.

In conclusion, in this "real life" study, HCC surveillance was associated with a smaller tumor size, earlier BCLC tumor stage, with impact on therapeutic strategy and was an independent predictor of increased survival.

\section{Conflicts of interest}

The authors who have taken part in this study declared that they do not have anything to disclose regarding funding or conflict of interest with respect to this manuscript.

\section{Authors' contributions}

Van Meer S, de Man RA, and van Erpecum KJ designed the study, collected patient data and wrote the manuscript; de Man RA, Coenraad MJ, Sprengers D, van Nieuwkerk CMJ, IJzermans JNM., Klümpen HJ, Jansen PLM, and Siersema PD collected patient data, critically revised the manuscript and contributed to the interpretation of the data and manuscript writing; van Meer S and van Oijen MGH performed statistical analyses; van Erpecum $\mathrm{KJ}$ and de Man RA supervised the manuscript. All authors approved the final version of the manuscript.

\section{Supplementary data}

Supplementary data associated with this article can be found, in the online version, at http://dx.doi.org/10.1016/j.jhep.2015.06. 012.

\section{References}

[1] Parkin DM, Bray F, Ferlay J, Pisani P. Global cancer statistics, 2002. CA Cancer J Clin 2005;55:74-108.

[2] Witjes CD, Karim-Kos HE, Visser O, van den Akker SA, de Vries E, Ijzermans $\mathrm{JN}$, et al. Hepatocellular carcinoma in a low-endemic area: rising incidence and improved survival. Eur J Gastroenterol Hepatol 2012;24:450-457.

[3] van Meer S, van Erpecum KJ, Schrier GH, Verhoef C, Verheij J, de Man RA, et al. Diagnostics and treatment of hepatocellular carcinoma in the Netherlands in the period 2003-2011. Ned Tijdschr Geneeskd 2014;158:A7074.

[4] Bruix J, Sherman M. Management of hepatocellular carcinoma: an update Hepatology 2011;53:1020-1022.

[5] EASL-EORTC clinical practice guidelines: management of hepatocellular carcinoma. J Hepatol 2012;56:908-943.

[6] Omata M, Lesmana LA, Tateishi R, Chen PJ, Lin SM, Yoshida H, et al. Asian Pacific Association for the Study of the Liver consensus recommendations on hepatocellular carcinoma. Hepatol Int 2010;4:439-474.

[7] Lederle FA, Pocha C. Screening for liver cancer: the rush to judgment. Ann Intern Med 2012;156:387-389.

[8] Zhang BH, Yang BH, Tang ZY. Randomized controlled trial of screening for hepatocellular carcinoma. J Cancer Res Clin Oncol 2004;130:417-422.
[9] Aghoram R, Cai P, Dickinson JA. Alpha-fetoprotein and/or liver ultrasonography for screening of hepatocellular carcinoma in patients with chronic hepatitis B. Cochrane Database Syst Rev 2012;9, CD002799.

[10] Chen JG, Parkin DM, Chen QG, Lu JH, Shen QJ, Zhang BC, et al. Screening for liver cancer: results of a randomised controlled trial in Qidong, China. J Med Screen 2003;10:204-209.

[11] Kansagara D, Papak J, Pasha AS, O’Neil M, Freeman M, Relevo R, et al. Screening for hepatocellular carcinoma in chronic liver disease: a systematic review. Ann Intern Med 2014;161:261-269.

[12] Singal AG, Pillai A, Tiro J. Early detection, curative treatment, and survival rates for hepatocellular carcinoma surveillance in patients with cirrhosis: a meta-analysis. PLoS Med 2014;11:e1001624.

[13] Singal A, Volk ML, Waljee A, Salgia R, Higgins P, Rogers MA, et al. Metaanalysis: surveillance with ultrasound for early-stage hepatocellular carcinoma in patients with cirrhosis. Aliment Pharmacol Ther 2009;30:37-47.

[14] Colli A, Fraquelli M, Casazza G, Massironi S, Colucci A, Conte D, et al. Accuracy of ultrasonography, spiral CT, magnetic resonance, and alphafetoprotein in diagnosing hepatocellular carcinoma: a systematic review. Am J Gastroenterol 2006;101:513-523.

[15] Santi V, Trevisani F, Gramenzi A, Grignaschi A, Mirici-Cappa F, Del PP, et al Semiannual surveillance is superior to annual surveillance for the detection of early hepatocellular carcinoma and patient survival. J Hepatol 2010:53:291-297.

[16] Han KH, Kim DY, Park JY, Ahn SH, Kim J, Kim SU, et al. Survival of hepatocellular carcinoma patients may be improved in surveillance interval not more than 6 months compared with more than 6 months: a 15-year prospective study. J Clin Gastroenterol 2013;47:538-544.

[17] Wang JH, Chang KC, Kee KM, Chen PF, Yen YH, Tseng PL, et al. Hepatocellular carcinoma surveillance at 4- vs. 12-month intervals for patients with chronic viral hepatitis: a randomized study in community. Am J Gastroenterol 2013;108:416-424.

[18] Trinchet JC, Chaffaut C, Bourcier V, Degos F, Henrion J, Fontaine H, et al. Ultrasonographic surveillance of hepatocellular carcinoma in cirrhosis: a randomized trial comparing 3- and 6-month periodicities. Hepatology 2011:54:1987-1997.

[19] Bruix J, Sherman M. Management of hepatocellular carcinoma. Hepatology 2005:42:1208-1236.

[20] Oken MM, Creech RH, Tormey DC, Horton J, Davis TE, McFadden ET, et al. Toxicity and response criteria of the Eastern Cooperative Oncology Group. Am J Clin Oncol 1982:5:649-655.

[21] Turati F, Galeone C, Rota M, Pelucchi C, Negri E, Bagnardi V, et al. Alcohol and liver cancer: a systematic review and meta-analysis of prospective studies. Ann Oncol 2014:25:1526-1535.

[22] Wiesner R, Edwards E, Freeman R, Harper A, Kim R, Kamath P, et al. Model for end-stage liver disease (MELD) and allocation of donor livers. Gastroenterology 2003;124:91-96

[23] Duffy SW, Nagtegaal ID, Wallis M, Cafferty FH, Houssami N, Warwick J, et al. Correcting for lead time and length bias in estimating the effect of screen detection on cancer survival. Am J Epidemiol 2008;168:98-104.

[24] Atkins D, Ross D, Kelley M. Acting in the face of uncertainty. Ann Intern Med 2014;161:300-301.

[25] El-Serag HB, Kramer JR, Chen GJ, Duan Z, Richardson PA, Davila JA. Effectiveness of AFP and ultrasound tests on hepatocellular carcinoma mortality in HCV-infected patients in the USA. Gut 2011;60:992-997.

[26] Tanaka H, Nouso K, Kobashi H, Kobayashi Y, Nakamura S, Miyake Y, et al. Surveillance of hepatocellular carcinoma in patients with hepatitis $C$ virus infection may improve patient survival. Liver Int 2006;26:543-551.

[27] Tong MJ, Sun HE, Hsien C, Lu DS. Surveillance for hepatocellular carcinoma improves survival in Asian-American patients with hepatitis B: results from a community-based clinic. Dig Dis Sci 2010;55:826-835.

[28] Wong GL, Wong VW, Tan GM, Ip KI, Lai WK, Li YW, et al. Surveillance programme for hepatocellular carcinoma improves the survival of patients with chronic viral hepatitis. Liver Int 2008;28:79-87.

[29] Cucchetti A, Trevisani F, Pecorelli A, Erroi V, Farinati F, Ciccarese F, et al. Estimation of lead-time bias and its impact on the outcome of surveillance for the early diagnosis of hepatocellular carcinoma. J Hepatol 2014;61:333-341.

[30] Schwartz M. A biomathematical approach to clinical tumor growth. Cancer 1961;14:1272-1294.

[31] Furlan A, Marin D, Agnello F, Di Martino M, Di Marco V, Lagalla R, et al. Hepatocellular carcinoma presenting at contrast-enhanced multi-detectorrow computed tomography or gadolinium-enhanced magnetic resonance imaging as a small $(</=2 \mathrm{~cm})$, indeterminate nodule: growth rate and optimal interval time for imaging follow-up. J Comput Assist Tomogr 2012;36:20-25. 
[32] Cucchetti A, Vivarelli M, Piscaglia F, Nardo B, Montalti R, Grazi GL, et al Tumor doubling time predicts recurrence after surgery and describes the histological pattern of hepatocellular carcinoma on cirrhosis. J Hepatol 2005;43:310-316

[33] Taouli B, Goh JS, Lu Y, Qayyum A, Yeh BM, Merriman RB, et al. Growth rate of hepatocellular carcinoma: evaluation with serial computed tomography or magnetic resonance imaging. J Comput Assist Tomogr 2005;29:425-429.

[34] Kubota K, Ina H, Okada Y, Irie T. Growth rate of primary single hepatocellular carcinoma: determining optimal screening interval with contrast enhanced computed tomography. Dig Dis Sci 2003;48:581-586.

[35] Sato T, Tateishi R, Yoshida H, Ohki T, Masuzaki R, Imamura J, et al Ultrasound surveillance for early detection of hepatocellular carcinoma among patients with chronic hepatitis C. Hepatol Int 2009;3:544-550.

[36] Sheu JC, Sung JL, Chen DS, Yang PM, Lai MY, Lee CS, et al. Growth rate of asymptomatic hepatocellular carcinoma and its clinical implications. Gastroenterology 1985;89:259-266.

[37] Vriend HJ, Op de Coul EL, van de Laar TJ, Urbanus AT, van der Klis FR, Boot HJ. Hepatitis C virus seroprevalence in the Netherlands. Eur J Public Health 2012;22:819-821.

[38] Baaten GG Sonder GJ, Dukers NH, Coutinho RA, Van den Hoek JA Population-based study on the seroprevalence of hepatitis $A, B$, and $C$ virus infection in Amsterdam, 2004. J Med Virol 2007;79:1802-1810.

[39] Hahne SJ, De Melker HE, Kretzschmar M, Mollema L, van der Klis FR, Van De Sande MA, et al. Prevalence of hepatitis B virus infection in The Netherlands in 1996 and 2007. Epidemiol Infect 2012;140:1469-1480.

\section{JOURNAL OF HEPATOLOGY}

[40] Davila JA, Morgan RO, Richardson PA, Du XL, McGlynn KA, El-Serag HB. Use of surveillance for hepatocellular carcinoma among patients with cirrhosis in the United States. Hepatology 2010;52:132-141.

[41] Singal AG, Nehra M, Adams-Huet B, Yopp AC, Tiro JA, Marrero JA, et al. Detection of hepatocellular carcinoma at advanced stages among patients in the HALT-C trial: where did surveillance fail? Am J Gastroenterol 2013; $108: 425-432$

[42] Davila JA, Henderson L, Kramer JR, Kanwal F, Richardson PA, Duan Z, et al. Utilization of surveillance for hepatocellular carcinoma among hepatitis $C$ virus-infected veterans in the United States. Ann Intern Med 2011;154:85-93.

[43] Trevisani F, Magini G, Santi V, Morselli-Labate AM, Cantarini MC, Di Nolfo MA, et al. Impact of etiology of cirrhosis on the survival of patients diagnosed with hepatocellular carcinoma during surveillance. Am J Gastroenterol 2007;102:1022-1031.

[44] Kuo YH, Lu SN, Chen CL, Cheng YF, Lin CY, Hung CH, et al. Hepatocellula carcinoma surveillance and appropriate treatment options improve survival for patients with liver cirrhosis. Eur J Cancer 2010;46:744-751.

[45] Tong MJ, Chavalitdhamrong D, Lu DS, Raman SS, Gomes A, Duffy JP, et al Survival in Asian Americans after treatments for hepatocellular carcinoma: seven-year experience at UCLA. J Clin Gastroenterol 2010;44:e63-e70.

[46] Cho SJ, Yoon JH, Hwang SS, Lee HS. Do young hepatocellular carcinoma patients with relatively good liver function have poorer outcomes than elderly patients? J Gastroenterol Hepatol 2007;22:1226-1231. 